\title{
Retardation of calcification of bovine pericardium used in bioprosthetic heart valves by phosphocitrate and a synthetic analogue
}

\author{
Jack W. Tsao and Frederick J. Schoen \\ Department of Pathology, Brigham and Women's Hospital, Department of Pathology, Harvard Medical School, Boston. \\ MA. USA
}

\author{
Ravi Shankar and John D. Sallis \\ Department of Biochemistry, University of Tasmania, Tasmania, Australia
}

\author{
Robert J. Levy \\ Department of Pediatric Cardiology, Department of Pediatrics and Communicable Diseases, University of Michigan Medical \\ School, Ann Arbor, MI, USA \\ (Received 1 April 1987; accepted 20 November 1987)
}

\begin{abstract}
The purpose of this study was to determine if phosphocitrate (PC). a naturally occurring inhibitor of calcification, and its synthatic analogue, $N$-sulpho-2-amino tricarballylate (SAT), administered either by daily injectinn or Incal delivery via Alzet osmotic minipump, could inhibit calcification of glutaraldehydepreserved bovine pericardium used in bioprosthetic heart valves, subcutaneously implanted in rats. Local drug delivery, but not systemic administration, was effective. PC, administered by Alzet minipump (12 mg. $\mathrm{kg}^{-1} \cdot \mathrm{day}^{-1}$ ), inhibited calcification significantly (tissue calcium $=\mathbf{5} \pm \mathbf{2} \mu \mathrm{g} / \mathrm{mg} \mathrm{dry}$ tissue, mean \pm SEM). compared with untreated or saline-treated controls $(89+9$ and $49+9 \mu \mathrm{g} / \mathrm{mg}$. respectively). SAT, administered by the same route at both the same and a higher molar dosage, was less potent (tissue calcium $=26 \pm 9 \mu \mathrm{g} / \mathrm{mg}$ and $17 \pm 5 \mu \mathrm{g} / \mathrm{mg}$, respectively). PC and SAT therapy were not associated with adverse effects. We conclude that locally administered PC and SAT can inhibit intrinsic calcification of bovine pericardium, with $\mathrm{PC}$ being more potent.
\end{abstract}

Keywords: Calcification, bioprosthesis, heart valve, pericardium

\begin{abstract}
Bioprosthetic heart valves fabricated from glutaraldehydepreserved porcine aortic valves or bovine parietal pericardium are commonly used to replace diseased human cardiac valves $^{1,2}$. Cuspal disruption with regurgitation and/or stiffening with stenosis due to intrinsic calcification frequently causes failure in porcine aortic valves. Re-operation is necessitated in at least $20-25 \%$ of adult recipients within 7-10 yrs post-operatively ${ }^{2-4}$, with calcification being more prominent in children ${ }^{5}$. Bovine pericardial bioprostheses, used more recently, also fail frequently due to mineralization ${ }^{6}$

Phosphocitrate (PC), a naturally occurring inhibitor of
\end{abstract}

Correspondence to: Dr Robert J. Levy, Kresge II, Room 5080, Box 0576, University of Michigan Medical Center, Ann Arbor, MI 48109-0576, USA. calcification $^{7,8}$, is a potent inhibitor of parathyroid hormoneinduced nephrocalcinosis ${ }^{9}$ and has recently been shown to be an anti-atherogenic agent ${ }^{10}$. A synthetic analogue of PC, $\mathrm{N}$-sulpho-2-amino tricarballylate (SAT), is also available, but SAT is a less potent calcification inhibitor than $\mathrm{PC}^{11}$. Systemic administration of $P C$ produces no known deleterious effects on bone growth ${ }^{7}$. Thus, PC may be a potent drug with few adverse effects. In contrast, the synthetic diphosphonates, such as ethanehydroxydiphosphonate (EHDP), previously shown to prevent pathological calcification of bioprosthetic tissue, produce severe adverse effects on bone and calcium metabolism when administered systemically ${ }^{12,13}$. The purpose of the present study was to investigate, using a wellcharacterized model of subcutaneous implantation in rats ${ }^{14,15}$. whether, and to what extent, bovine pericardial calcification

(9) 1988 Butterworth \& Co (Publishers) Ltd. 0142-9612/88/050393-05\$03.00 
could be inhibited by these drugs, administered via daily systemic injection or site-specific therapy via locally placed osmotic drug delivery systems.

\section{MATERIALS AND METHODS}

Parietal pericardium, obtained from 2-3 wk-old calves, was rinsed with ice-cold isotonic saline ( $0.9 \%$ saline), placed

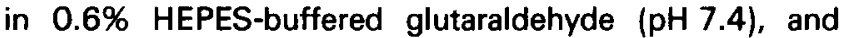
transferred to $0.2 \%$ glutaraldehyde in the same buffer after $24 \mathrm{~h}$, for storage at $2^{\circ} \mathrm{C}$. Superficial fat was removed by blunt dissection and the tissue was rinsed with isotonic saline and double-distilled water before implantation.

PC was synthesized and characterized according to previously described methods ${ }^{16.17}$; SAT was synthesized as indicated by Brown and Sallis ${ }^{11}$. The sodium salts of both compounds were used. PC, SAT and saline were prepared at a concentration of $0.06 \mathrm{M}$ for daily subcutaneous injection, similar to that used in a previous study with EHDP ${ }^{12}$. There were four injection groups, including a high-dosage and a low-dosage group for both PC and SAT. Controls included saline injected at an ionic concentration equivalent to the molar dosage of the high-dosage PC group and no injection (untreated). Drugs were injected at a dosage of 27 and $2.7 \mathrm{mg} \cdot \mathrm{kg}^{-1} \cdot \mathrm{day}^{-1}$ PC, 24 and $2.4 \mathrm{mg} \cdot \mathrm{kg}^{-1}$.day ${ }^{-1}$ SAT, and $62 \mathrm{mg} \cdot \mathrm{kg}^{-1}$.day ${ }^{-1}$ saline, based on animal weights measured daily. These doses were selected to correspond with the dosage optima (on a molar basis) for EHDP administered by the same route ${ }^{12}$. For studies of local therapy, PC, SAT, and saline, at concentrations of $0.22 \mathrm{M}$ each and, in addition, $1.26 \mathrm{M}$ for SAT (saturated) were loaded into Alzet 2002 drug delivery systems ${ }^{a}$. On the basis of calibration data supplied by the manufacturer, Alzets were calculated to deliver approximately $12 \mathrm{mg} \cdot \mathrm{kg}^{-1} \cdot \mathrm{day}^{-1} \mathrm{PC}, 11$ and $94 \mathrm{mg} \cdot \mathrm{kg}^{-1} \cdot \mathrm{day}^{-1} \mathrm{SAT}$, and $15 \mathrm{mg} \cdot \mathrm{kg}^{-1} \cdot \mathrm{day}^{-1}$ saline. This molar dosage was equivalent to that of EHDP used in previous experiments ${ }^{12}$.

As in previous studies ${ }^{10,14}, 3$-wk-old male CD SpragueDawley rats ${ }^{\mathrm{b}}$, weighing $65-110 \mathrm{~g}$, and fed Lab Chow ${ }^{c}$, were used. Surgery was done under ether anaesthesia. In the injection experiment, each of five rats received two pieces of tissue $(1 \mathrm{~cm} \times 1 \mathrm{~cm})$, implanted in subcutaneous pockets dissected in the ventral abdominal wall. Each of 10 rats in each minipump group received, in a pocket dissected dorsally, one minipump with the tissue sutured near the removable pump head. In addition to the saline controls, five rats had two pieces of pericardium implanted subcutaneously in pockets dissected in the ventral abdomenal wall, serving as untreated controls. After $14 \mathrm{~d}$, rats were killed using an overdose of pentobarbital (Nembutal), and tissue was explanted. Representative femurs were removed to assess bone growth plate morphology (distal femoral epiphysis). Blood sampling was done by cardiac puncture.

For histological examination, a portion of each piece of explanted tissue was placed immediately in Karnovsky's fixative $(0.1 \mathrm{M}$ cacodylate-buffered $2.5 \%$ glutaraldehyde, $2 \%$ paraformaldehyde, $\mathrm{pH} 7.2)^{18}$, and dehydrated after $24 \mathrm{~h}$ using a series of graded alcohols, with final storage in $100 \%$ ethanol. Femurs were fixed in $10 \%$ phosphatebuffered formalin, and dehydrated in a series of graded alcohols. Pericardial and bone specimens for light micro-

\footnotetext{
aAlza Corporation, Stanford, CA, USA.

${ }^{b}$ Charles River Laboratories, Burlington, MA, USA

'Ralston Purina, St Louis, MO, USA

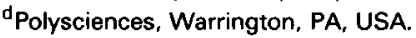

scopy were embedded in JB-4 glycolmethacrylate medium ${ }^{\text {d }}$, sectioned to 2-3 $\mu \mathrm{m}$, and stained with haematoxylin and eosin (for overall morphology) and von Kossa's stain (for calcium phosphates).

For biochemical analysis, retrieved tissue was rinsed in sterile, isotonic saline, washed free of salts using doubledistilled water, lyophilized, pulverized to a fine powder, and then dried to a constant weight in a desiccator oven. The tissues were subjected to acid hydrolysis using $6 \mathrm{~N} \mathrm{HCl}$ for $24 \mathrm{~h}$ and dried under air, using a water bath. Dried hydrolysates were then redissolved with $0.01 \mathrm{~N} \mathrm{HCl}$. Mineral analyses on the hydrolysates determined tissue calcium content, using atomic absorption spectroscopy, and tissue phosphorous content, assayed according to the methodology of Chen ${ }^{19}$. Serum calcium was determined by atomic absorption spectroscopy. Elemental concentrations were expressed in $\mu \mathrm{g}$ per $\mathrm{mg}$ dry tissue weight, mean \pm standard error of the mean. The Student's $t$-test was performed to determine statistical significance.

\section{RESULTS}

Intrinsic calcification of glutaraldehyde-pretreated pericardial tissue implants was reduced by PC and SAT, administered using Alzets (Figures 1 and 2), with no apparent adverse effects on bone or calcium metabolism (Figure 3). The calcium contents of both the PC and low-dosage SAT minipump treated tissues $(5+2 \mu \mathrm{g} / \mathrm{mg}$ dry tissue and $26+9 \mu \mathrm{g} / \mathrm{mg}$, respectively) were significantly lower than those of the saline controls $(49+9 \mu \mathrm{g} / \mathrm{mg})(\rho<0.001)$ and the untreated controls $(p<0.001)$ (Figure 1). Unimplanted bovine pericardium has approximately $1 \mu \mathrm{g} / \mathrm{mg}$ calcium $^{14}$. The high-dosage SAT minipump group showed levels of calcium $(17 \pm 5 \mu \mathrm{g} / \mathrm{mg})$ comparable to those of the low-dosage SAT group. In contrast, injection therapy with both PC and SAT at high and low dosages was ineffective in preventing accumulation of mineral (Table 1 and Figure 2). Light microscopy of removed pericardial tissue, illustrated in Figure 2, confirmed the chemical data. In all animals, including both Alzet and injection therapy groups, bone epiphyseal growth plates had normal morphology (Figure 3). Serum calcium content and animal weights at killing were unaffected by treatment with PC and SAT, and were identical to those of control animals (data not shown).

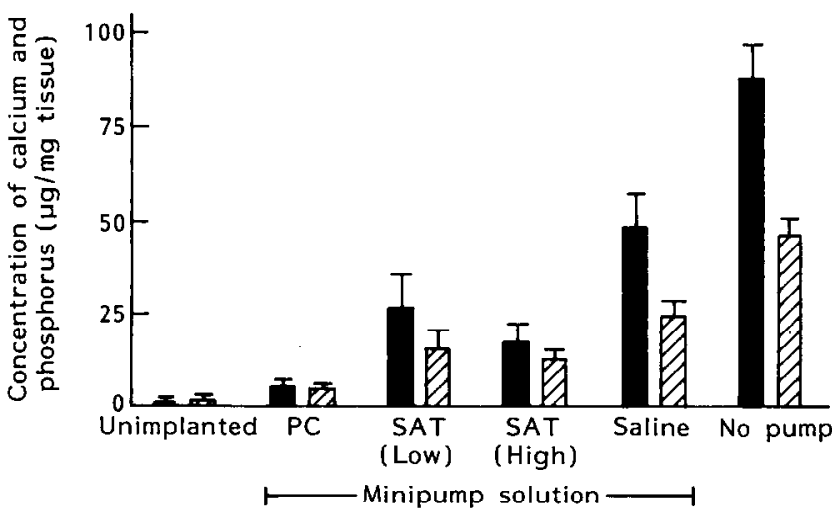

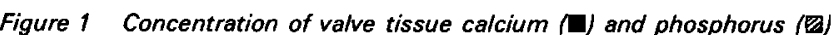
after minipump drug therapy with phosphocitrate $(P C)$ and sulphaminotricarballylate (SAT). Data for unimplanted pericardium, shown for comparison, are from Ref. 14 


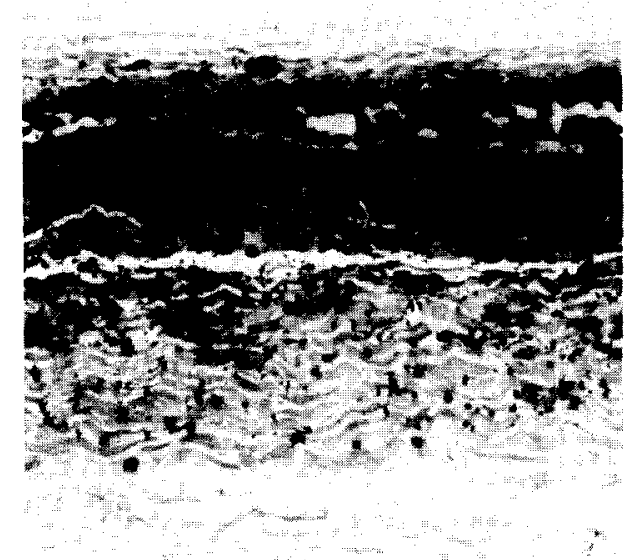

a

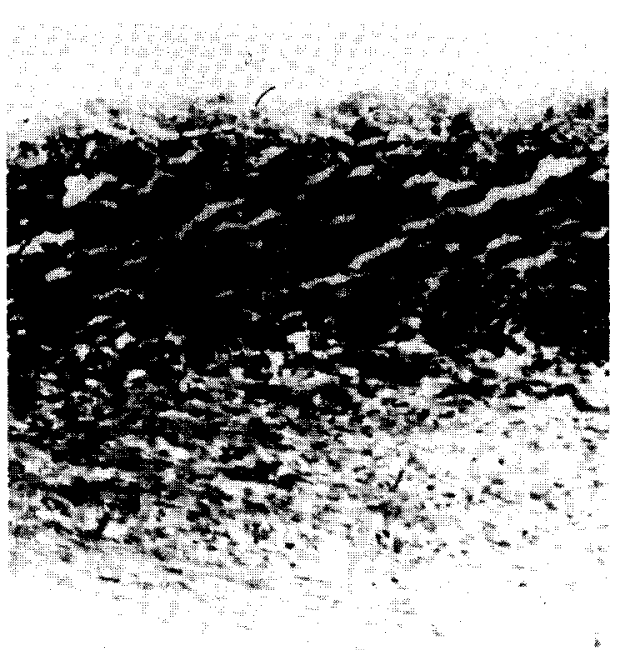

b

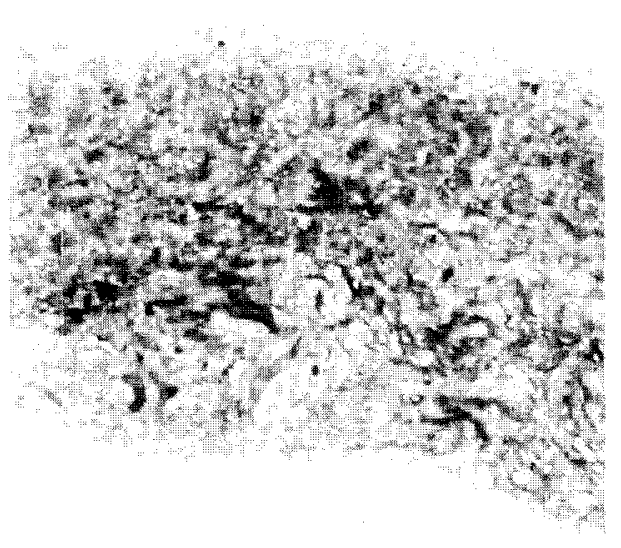

Figure 2 Photomicrographs of valve cusps removed from unimplanted, control, and treated groups. (a) Control implant removed after 14 d. (b) Implant treated using injection of high-dos age phosphocitrate (PC). (c) Vatve tissue treated using PC administered via Alzet. (d) Bovine pericardium after treatment with high-dose sulphaminotricarballyate (SAT) via Alzet. Note markedly reduced mineralization in (c) and (d). Stained using von Kossa's reagent (calcium phosphate is blackl. $\times 200$.

Table 1 Effects of injected phosphocitrate $(P C)$, sulphaminotricarballyate (SAT) and saline on the calcium and phosphorus content of treated pericardial tissues following subcutaneous implantation in rats for 2 wks

\begin{tabular}{llll}
\hline Group & Number & Calcium & Phosphorus \\
\hline PC $\left(27 \mathrm{mg} \mathrm{kg}^{-1}\right.$ day $\left.^{-1}\right)$ & 10 & $89 \pm 6$ & $50 \pm \mathbf{3}$ \\
PC $\left(2.7 \mathrm{mg} \mathrm{kg}^{-1} \mathrm{day}^{-1}\right)$ & 10 & $86 \pm 16$ & $45 \pm 7$ \\
SAT $\left(24 \mathrm{mg} \mathrm{kg}^{-1}\right.$ day $\left.^{-1}\right)$ & 10 & $74 \pm 10$ & $43 \pm 6$ \\
SAT $\left(2.4 \mathrm{mg} \mathrm{kg}^{-1} \mathrm{day}^{-1}\right)$ & 10 & $99 \pm \mathbf{5}$ & $53 \pm 4$ \\
Saline & 10 & $93 \pm 11$ & $58 \pm 7$ \\
Control & 12 & $\mathbf{8 9} \pm \mathbf{8}$ & $53 \pm 4$ \\
\hline
\end{tabular}

Data are expressed as mean $\mu \mathrm{g} \mathrm{mg}^{-1}$ dry tissue weight $\pm \mathrm{SEM}$.

\section{DISCUSSION}

This study demonstrated that PC, a physiological inhibitor of mineralization, was a potent inhibitor of bovine pericardial tissue calcification in subcutaneous implants in rats, when administered locally at a concentration of $12 \mathrm{mg} \cdot \mathrm{kg}^{-1}$.day ${ }^{-1}$. Tissue calcium contents following local treatment with PC were comparable to those of a previous study with EHDP injected at a dosage equivalent to the molar $\mathrm{PC}$ minipump dosage $^{12}$, in agreement with previous studies comparing PC with EHDP in preventing aortic calcification ${ }^{20}$. SAT, although a weaker calcification inhibitor than $\mathrm{PC}$, also significantly inhibited calcification, with the levels of calcium following $14 \mathrm{~d}$ implantation being approximately equal to those of typical $3 \mathrm{~d}$ implants in this model ${ }^{14}$. That the saline-loaded Alzet experiments also had modestly reduced mineralization suggests that the physical presence of the Alzets may have affected the accumulation of calcium phosphates in the pericardial tissue implants of the saline control group. A previous study in which Alzet saline infusions were carried out demonstrated no detectable effect on bioprosthetic leaflet and daily subcutaneous injections of saline also had no effect ${ }^{17}$. It is possible that physical compression of the bioprosthetic tissue by the Alzet drug delivery system may be causing some inhibition of calcification, since compressive stress has been recently shown to focally inhibit the formation of bioprosthetic calcific deposits ${ }^{21}$.

Although a higher injection dosage of SAT was minimally effective, injected drugs did not significantly 

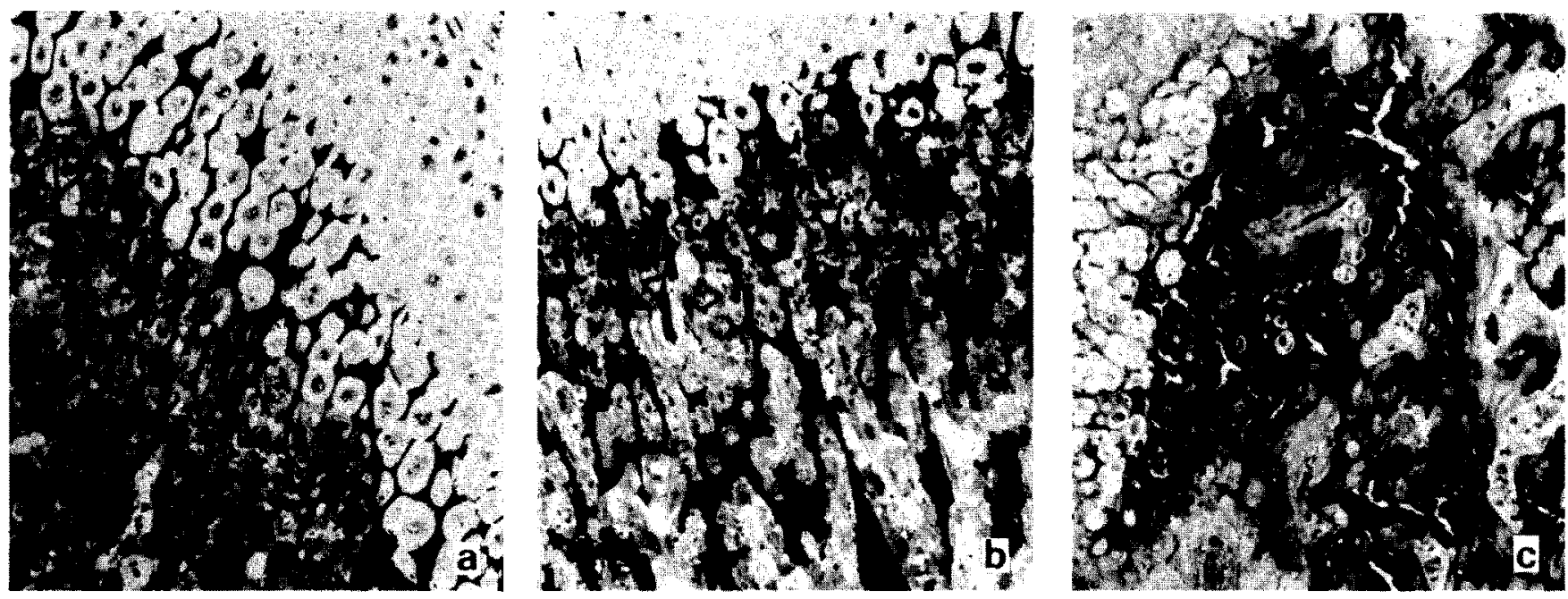

Figure 3 Photomicrographs of undecalcified sections of epiphyseal growth plate of distal femurs from rats. (a) Control. (b) PC minipump. (c) EHDP injection. (c) Is photo from experiments reported in Ref. 12. The epiphyseal bone growth plate of (b) is normal and similar in structure to control. In (c), note the poorly mineralized, widened trabeculae. PC and SAT injection and SAT minipump drug delivery also had no detrimental effects on bone growth plates (data not shown). Stained with von Kossa's reagent. $\times 150$.

reduce tissue mineralization. Possible explanations for this are that the dosages were not concentrated enough to be effective systemically, whereas the concentration of the drugs in the vicinity of the implant with local administration was quite effective, or that $\mathrm{PC}$ was metabolized before action at the implant site. Although these results suggest a lack of efficacy of injected PC and SAT, other therapeutic regimens could possibly provide adequate drug levels.

Synthetic diphosphonates, such as EHDP, have been shown to be potent inhibitors of bioprosthetic tissue calcification in rats, but systemic clinical use would be limited by adverse effects on bone growth ${ }^{12,13}$. Although local administration of diphosphonates by Alzet is effective and minimizes these adverse effects ${ }^{12,13}, \mathrm{PC}$ may be more advantageous than EHDP since it is a naturally occurring compound with few side effects ${ }^{7,8}$. Bone growth plates were not damaged by local administration of $\mathrm{PC}$ or by systemic injections of $P C$ at a level of $50 \mathrm{mg} \cdot \mathrm{kg}^{-1}$.day ${ }^{-1}$ for up to $90 \mathrm{~d}$ (R. Shankar and J.D. Sallis, unpublished data). Unlike EHDP, which is not biodegradable and, therefore, can accumulate in bone and become toxic, PC is probably catabolized to non-toxic products in the bone via phosphatases and does not affect somatic growth ${ }^{8}$.

Physiological solutions supersaturated with respect to calcium and phosphorus, such as plasma or lymph, are metastable, and hydroxyapatite precipitation does not occur spontaneously within them due to physiological inhibitors ${ }^{22}$. It is unknown whether pathological mineralization in bioprosthetic tissue occurs because of the absence of naturally occurring inhibitors. Nevertheless, this study suggests that local restoration of inhibitors will prevent mineralization.

The mechanisms of action of PC and SAT are unknown. Structural factors have been suggested ${ }^{16.23-25}$ However, the action of $\mathrm{PC}$ is unlikely to be directly related to calcium chelation, since PC binds calcium insignificantly ${ }^{26}$ Degradation of PC by phosphatases or hydrolysis of the phosphoester bond yields phosphate and citrate ${ }^{24}$. The degradation of $\mathrm{PC}$ to these physiological compounds probably accounts for its lack of adverse effects. Although less effective than PC, SAT may be an effective compound in controlling calcification. SAT is water soluble, possesses excellent oral absorptive properties, and is resistant to enzyme degradation ${ }^{27}$. The pharmacokinetics for the oral absorption of PC have not yet been fully characterized. PC, because it can be easily hydrolysed, especially in the kidneys ${ }^{8}$, probably cannot be administered orally with as much effectiveness as SAT via this route.

The long-term goal of calcification inhibition would be application of a preventive therapy to clinical valve replacements. As with our previous work, the present study utilized subcutaneous implants in rats ${ }^{12-15}$. It is logical to use subcutaneous implants in rats to investigate the pathophysiology of bioprosthetic valve calcification because, with this method, it is possible to screen rapidly specific hypotheses for their ability to inhibit intrinsic calcification. The most promising approaches, such as local PC therapy, may then be tested in the circulatory environment. In circulatory models, however, PC may not function in the same manner or with the same effectiveness, since constant blood flow and humoral factors might modulate its sitespecific effect. In humans, more PC may be required to regulate the rate of calcification, and it might not be possible to accomplish this without compromising other regulatory systems which involve calcium. Thus, local administration of the drug might be crucial. Since both PC and SAT are relatively stable (PC and SAT do remain active over a $28 \mathrm{~d}$ period when stored inside the Alzet at body temperature; R. Shankar and J.D. Sallis, unpublished data), it might be possible to prevent calcification by modifying future valve replacements to include a controlled-release polymer matrix loaded with the drugs in the sewing ring ${ }^{28}$. The longevity of the anticalcification effects of controlled drug delivery of $P C$ or SAT is unknown. However, comparable studies of the controlled release of EHDP (for 2 wks via Alzet administration) indicate continued protection against calcification for an additional 3 wks following depletion of the drug supply.

In conclusion, both PC and SAT significantly inhibited calcification of pericardial bioprosthetic tissue, subcutaneously implanted in the rat, when administered via local controlled-release drug delivery. Inhibition of pericardial implant calcification with either PC or SAT was not associated with any detectable adverse effects. Injection therapy with these agents was ineffective. Therapy with PC or SAT used in controlled-release drug delivery devices could eventually be of clinical importance, especially since these compounds 
have fewer associated adverse effects than other wellknown anticalcification agents such as EHDP.

\section{ACKNOWLEDGEMENTS}

We thank S.A. Lund, J.A. Linden, M.S. Smith, S. Murray and $H$. Shing for expert technical assistance. This work was supported in part by an NIH Grant, HL 24463. Dr Levy is an Established Investigator of the American Heart Association. We also thank Mrs Catherine Wongstrom for preparing this manuscript.

\section{REFERENCES}

1 Cohn, L.H. and Gallucci, V., Cardiac Bioprostheses, Yorke Medical Books, New York, 1982, 1-591

2 Schoen, F.J. and Levy, R.J., Bioprosthetic heart valve failure: pathology and pathogenesis, Cardiol. Clin. 1984, 2, 717-739

3 Milano, A., Bartolotti, U., Talenti, E., Valfre, C., Arbustini, E., Valente, M., Mazzucco, A., Gallucci, V. and Thiene, G., Calcific degeneration as the main cause of porcine bioprosthetic valve dysfunction, Am. J. Cardiol. 1984, 53, 1066-1070

4 Oyer, P.E., Stinson, E.B., Miller, D.C., Jamieson, S.W., Mitchell, R.S and Shumway, N.E., Thromboembolic risk and durability of the Hancock bioprosthetic cardiac valve, Eur. Heart J. 1985, 5 (suppl D), 81-85

5 Sanders, S.P., Levy, R.J., Freed, M.D., Norwood, W.I. and Castaneda, A.R., Use of Hancock porcine xenografts in children and adolescents. Am. J. Cardiol. 1980, 46, 429-438

6 Reul, G.J., Cooley, D.A., Duncan, J.M., Frazier, O.H., Hallman, G.L., Livesay, J.J., Ott, D.A. and Walker, W.E., Valve failure with the Ionescu-Shiley bovine pericardial bioprosthesis: analysis of 2680 patients. J. Vasc. Surg. 1985, 2, 192-204

7 Tew, W.P., Malis, C.D., Lehninger, A.L., Walker, G.W. and Howard J.E., Inhibition of PTH-induced nephrocalcinosis by phosphocitrate, in Urolithiasis (Eds L.H. Smith, W.G. Robertson and B. Finlayson), Plenum Press, New York, 1981, 559-568

8 Williams, G. and Sallis, J.D., The sources of phosphocitrate and its role as an inhibitor of calcium phosphate and calcium oxalate crystallization, in Urolithiasis (Eds L.H. Smith, W.G. Robertson and B. Finlayson), Plenum Press, New York, 1981, 569-577

9 Tew, W.P., Malis, C.D., Howard, J.E. and Lehninger, A.L., Phosphocitrate inhibits mitochondrial and cytosolic accumulation of calcium in kidney cells in vivo, Proc. Natl Acad. Sci. USA 1981, 78, 5528-5532

10 Shankar, R., Tuyethong, N. and Sallis, J.D., Atherogenesis: mitigation of monocyte adhesion to arterial endothelium in hyperlipidemic rats by phosphocitrate, a phosphorylated polycarboxylic acid, Atherosclerosis 1986, 62, 47-54

11 Brown, M.R. and Sallis, J.D., The synthesis and characterization of $N$ - sulfo-2-amino tricarballylate: an analog of phosphocitrate and inhibitor of calcification, Anal. Biochem. 1983, 132, 115-123

12 Levy, R.J., Hawley, M.A., Schoen, F.J., Lund, S.A. and Liu, P.Y., Inhibition by diphosphonate compounds of calcification of porcine bioprosthetic heart valve cusps implanted subcutaneously in rats. Circulation 1985, 71, 349-356

13 Levy, R.J., Wolfrum, J., Schoen, F.J., Hawley, M.A., Lund, S.A. and Langer, R., Inhibition of calcification of bioprosthetic heart valves by local controlled-release diphosphonate, Science 1985, 228, 190-192

14 Schoen, F.J., Tsao, JW and Levy, R.J., Calcification of bovine pericardium used in cardiac valve bioprostheses: role of glutaraldehydemodified structural components in bioprosthetic tissue mineralization, Am. J. Pathol. 1986, 123, 134-145

15 Levy, R.J., Schoen, F.J., Levy, J.T., Nelson, A.C., Howard, S.L. and Oshry, L.J., Biologic determinants of dystrophic calcification and osteocalcin deposition in glutaraldehyde-preserved porcine aortic valve leaflets implanted subcutaneously in rats, Am. J. Pathol. 1983 113, 134-155

16 Tew, W.P. Mahle, C., Beravides, J., Howard, J.E. and Lehninger, A.L. Synthesis and characterization of phosphocitric acid, a potent inhibitor of hydroxylapatite crystal growth, Biochem. 1980, 19, 1983-1988

17 Williams, G. and Sallis, J.D., The synthesis of unlabeled and 32P labeled phosphocitrate and analytical systems for its identification, Anal. Biochem. 1980, 102, 365-373

18 Karnovsky, M.J., A formaldehyde-glutaraldehyde fixative of high osmolarity for use in electron microscopy, J. Cell Biol. 1965, 27 137A-138A (abstract)

19 Chen, P.S., Toribara, T.Y. and Warner, H., Microdetermination of phosphorus, Anal. Chem. 1956, 28, 1756-1758

20 Shankar, R., Crowden, S. and Sallis, J.D., Phosphocitrate and its analogue $\mathrm{N}$-sulpho-2-amino tricarballylate inhibit aortic calcification, Atherosclerosis 1984, 52, 191-198

21 Tsao, J.W., Levy, R.J. and Schoen, F.J., Compressive mechanical deformation inhibits calcification of bovine pericardium used in cardiac valve bioprostheses, Trans. Soc. Biomat. 1987, 13, 180

22 Boskey, A.L., Current concepts of the physiology and biochemistry of calcification, Clin. Orthop. 1981, 157. 237-260

23 Williams, G. and Sallis, J.D., Structure-activity relationship of inhibitors of hydroxyapatite formation, Biochem. J. 1979, 184, $181-184$

24 Williams, G. and Sallis, J.D., Structural factors influencing the ability of compounds to inhibit hydroxyapatite formation, Calcif. Tissue Int 1982, 34, 169-177

25 Howard, J.E., Studies on urinary stone formation: a saga of clinical investigation, Johns Hopkins Med. J. 1976, 139, 239-252

26 Lehninger, A.L., The possible role of mitochondria and phos phocitrate in biological calcification, in Biomineralization and Biological Metal Accumulation (Eds P. Westbroek and E.W. De Jong). Reide Publishing Company, Boston, 1983, 107-122

27 Brown, M.R. and Sallis, J.D., N-sulfo-2-amino tricarballylate, a new analog of phosphocitrate: metabolic studies and inhibitory effects on renal calcification, in Urolithiasis and Related Clinical Research (Eds P.O. Schwille, L.H. Smith, W.G. Robertson and W. Vahlensieck), Plenum Press, New York 1985, 891-894

28 Levy, R.J., Schoen, F.J. and Golomb, G., Bioprosthetic heart valve calcification: clinical features, pathobiology, and prospects for prevention, CRC Critical Reviews in Biocompatibility 1986, 2 , 147-187 